\title{
Screening for Antioxygenic Compounds in Marine Algae and Bromophenols as Effective Principles in a Red Alga Polysiphonia ulceolate
}

\author{
Kenshiro Furimoto, ${ }^{*}$ Hiroko OHmura, ${ }^{*}$ and Takashi KanedA*
}

(Accepted December 3, 1984)

\begin{abstract}
As a result of screening for antioxygenic principles in marine algae, the effects of two types of red algae, Polysiphonia urceolata and Gelidium divaricatum, were found to be clearly superior to those of brown algae.

Bromophenols with 5-bromo-3,4-dihydroxy benzaldehyde (I) as the main constituent were identified as the effective principles in $P$. urceolata.

Two types of bromophenols found in $P$. urceolata, (I) and 5-bromo-3,4-dihydroxy benzylalcohol, were synthesized and their antioxidant activities compared with several natural and synthetic antioxidants by the following methods: (1) the oven test, (2) oxygen absorption in emulsion, (3) the Active Oxygen Method, (4) the chemiluminescence method. Both of the bromophenols showed considerable antioxidant activity in these tests at low temperature, however, their effects at higher temperatures were poor.
\end{abstract}

Previously, one of the authors reported that the phospholipids contained in Porphyra tenera showed antioxidant activity. ${ }^{1)}$ By successive screening tests for antioxygenic principles in marine algae, more than half of them showed those effects. ${ }^{2)}$ Especially, the chloroform-soluble fractions extracted from several species of brown algae, Eisenia bicyclis and Undaria pinnatifida, showed excellent antioxygenic activities. ${ }^{2)}$

We have continued the screening tests for antioxygenic principles in marine algae, and found that a red alga which belongs to genus Palysiphonia, shows a marked antioxidant activity. Further, we determined the chemical structures of the antioxygenic compounds in Polysiphonia and compared their activities under various conditions with several natural and synthetic antioxidants.

\section{Materials and Methods}

\section{Materials}

Nineteen species of marine algae ( 5 brown algae and 14 red algae) collected at Onagawa and Kitakami (Miyagi Prefecture, Japan) in May were examined. Algae were washed with fresh water, air-dried, pulverized and kept in a freezer.

As the substrate oil for the screening test, the methyl ester of safflower oil, free from unsaponifiables, was used. Its fatty acid composition was as follows: linoleate $77 \%$, oleate $14 \%$, palmitate and stearate $9 \%$.

\section{Preparation of Algal Extracts for Stability Tests}

Samples were extracted from dried algae ( $5 \mathrm{~g}$ ) with $50 \mathrm{ml}$ of chloroform/methanol (2:1) a total of three times. Extracts were combined and mixed with water, giving a chloroform-soluble fraction and an aqueous methanol fraction. The chloroform-soluble fraction was treated with acetone and fractionated into acetone-soluble and -insoluble fractions.

Screening for Antioxidant Activities of Algal Extracts

The antioxidant activity of each algal extract was assayed by the oven test according to the method of OLCOTT and EINSETT ${ }^{3 /}$ with some modification. An aliquot $(5 \mathrm{mg}$ ) of the chloroformsoluble fraction was put into a $10-\mathrm{m} l$ beaker; $500 \mathrm{mg}$ of substrate ester were added and well mixed with the sample. Beakers were stored at $45^{\circ} \mathrm{C}$, and weighed daily until the induction period had ended and the substrate had attained a weight gain of $10 \mathrm{mg}$.

Fractionation of Antioxygenic Substances from Polysiphonia urceolata

The acetone-soluble fraction of $\boldsymbol{P}$. urceolata was

* Department of Food Chemistry, Faculty of Agriculture, Tohoku University, Tsutsumidori-Amamiya-

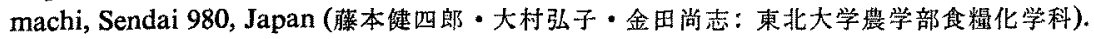


fractionated chromatographically on a Sephadax LH-20 (Pharmacia) column. The column was eluted with the mixture of chloroform/methanol, increasing the ratio of methanol in steps (Table 2). The fraction eluted with methanol was analyzed by TLC (Polyamide 11 F254, methanol/water 9:1 $\mathrm{v} / \mathrm{v}$ ) to detect the active principles using the method of Selvo et al. ${ }^{3}$ The active fraction was also analyzed by gas chromatography (GC) and gas chromatography-mass spectrometry (GC-MS) after trimethylsililation with TMS-BA (Tokyo Kasei). Analyses of TMS derivatives were carried on a JEOL model 1100 equipped with flame ionization detectors and a $2 \mathrm{~m}, 4 \mathrm{~mm}$ i.d. glass column packed with $3 \%$ SE-30 on a $80 / 100$ mesh Chromosorb W. Column temperature was programmed from $160-280^{\circ} \mathrm{C}$ at $3^{\circ} \mathrm{C} / \mathrm{min}$. Injector and detector temperature were held at 250 and $280^{\circ} \mathrm{C}$ respectively. The mass spectra (MS) were determined with a Hitachi RMU-6MG. Ionization voltage was $20 \mathrm{eV}$.

Preparation of 5-Bromo-3,4-dihydroxy Benzaldehyde (BrPhenolCHO), 5-Bromo-3,4-dihydroxy Benzylalcohol (BrPhenol $\mathrm{CH}_{2} \mathrm{OH}$ ), and $\mathrm{N}$-Vanillyl Octadecanamide

BrPhenolCHO was synthesized from protocatechualdehyde (Tokyo Kasei) by the method described by PsCHORR, ${ }^{3)}$ and recrystallized from $50 \%$ ethanol. $\mathrm{BrPhenolCH}_{2} \mathrm{OH}$ was prepared from BrPhenolCHO by reduction with $\mathrm{NaBH}_{4}$ according to the method of GlombitzA et al.$^{\left.{ }^{6}\right)}$ The synthesized bromophenols gave a single spot on TLC, and their purities were also confirmed by elementary analysis.

$N$-Vanillyl octadecanamide was synthesized as described previously.")

Comparison of Antioxidant Activities of Synthetic Bromophenols

Antioxidant activities of synthetic bromophenols were assayed by the following methods, with comparison to butyl hydroxyanisole (BHA), prototocatechualdehyde and $N$-vanillyl octadecanamide.

1) Oven test. As described for the screening test, the length of the induction period of the substrate oil was determined by the method of OLCOTT and EINSTETT. ${ }^{3)}$ In this experiment, the stripped corn oil (Eastman Kodak), free from tocopherols, was used in place of the methyl ester of safflower oil used in the screenings.
2) Active Oxygen Method (AOM) The stabilities of lard samples to which antioxidant was added were measured at $97.8^{\circ} \mathrm{C}$ with constant airation according to the Tentative Method of the American Oil Chemists' Society (Cd 12-57).

3) Antioxidant activities in emulsion were evaluated by the method described by $\mathrm{YAGl}^{8)}$ with some modification.

One hundred $g$ of stripped corn oil, described above, was emulsified with $300 \mathrm{~m} l$ of distilled water and $5 \mathrm{~g}$ of Tween 40 . Fifty $\mathrm{g}$ of the emulsion were put into a $50 \mathrm{~m} l$-erlenmeyer flask with a stopper, and well shaken with an aliquot of antioxidant sample. After addition of $0.5 \mathrm{~m} l$ of $1 \%$ $\mathrm{FeSO}_{4}$ solution, the oxygen content in the emulsion kept at $30^{\circ} \mathrm{C}$ was measured polarographically with a Beckmann Monitor System (model 12301).

4) Chemiluminescence method According to the method of ENDo et al.,* antioxidant activity for photosensitized oxidation was evaluated using a chemiluminescence analyzer. Five $g$ of the methyl ester of safflower oil were put into a cell and mixed with $1 \mathrm{mg}$ of antioxidant and $0.5 \mathrm{~m} /$ of chlorophyll a solution $(3.2 \mathrm{mg} / 25 \mathrm{~m} l$ in acetone/ hexane (1:1)). After irradiation with a $500 \mathrm{~W}$ tungsten lamp at $0^{\circ} \mathrm{C}$ for $15 \mathrm{~min}$, the emission intensity of the ester was measured for $30 \mathrm{~s}$ using an ultra weak chemiluminescence analyzer OX-7 (Tohoku Electronic Industries).

\section{Results and Discussion}

\section{Antioxygenic Activities of Marine Algae}

In this screening test, only the chloroformsoluble fractions were assayed for antioxidant activity because the activities of the other fractions (aqueous-methanol and residues) had been shown to be very weak.) As a result, contrary to the previous screening, ${ }^{2)}$ in which the extracts of brown algae had been more effective than those of red algae, the effects of two species of red algae, Polysiphonia urceolata and Gelidium divaricatum, were found to be superior. By addition of the extracts of these algae at a $1 \%$ level, the induction periods of the substrate was extended to 73 days with $P$. urceolata and 31 days with $G$. divaricatum. Under the same conditions, the induction period of substrate without addition of the extract was 3 days, while to which the extracts of other algae were within the range of 6 to 16 days. The effect of $P$. urceolata was the strongest of all marine

* Y. ENDo, R. UsuKI, and T. KanEDA: Abstracts of 28th Annual Meeting of the Japan. Soc. Food Technol., Fukuoka, p. 33, 1981. 
algae ever examined.

Purification of the Antioxygenic Principles in Polysiphonia urceolata

Polysiphonia urceolata is widely distributed along the intertidal zone of the Japanese coast, but is not commonly used for food. As shown in Table 1 , the antioxygenic substances were found in the acetone-soluble fraction. It was proven that the active principles were not phospholipids. The acetone-soluble fraction was further fractionated by chromatography on a Sephadex LH-20 column (Table 2). The most pronounced antioxidant activity was found in the fraction eluted with methanol. On TLC, this fraction gave three antioxygenic spots, ${ }^{4)}$ with $\mathrm{Rf}$ values $=0.09-0.14$, 0.25 and 0.37 all of which absorbed UV light. Two major spots with higher $\mathrm{Rf}$ values reacted positively with ferric chloride reagent ${ }^{9)}$ and in the

Table 1. Antioxidant activities of the lipid fractions extracted from Polysiphonia urceolata at a $1 \%$ concentration

\begin{tabular}{lc}
\hline Fraction & $\begin{array}{c}\text { Induction period } \\
\text { (days) of the } \\
\text { substrate at } 45^{\circ} \mathrm{C}\end{array}$ \\
\hline Control (without addition) & 3 \\
Aqueous methanol & 4 \\
Chloroform & 76 \\
Acetone-soluble & 80 \\
Acetone-insoluble & 10 \\
\hline
\end{tabular}

Table 2. Fractionation of the acetone-soluble fraction on a Sephadex LH-20 column, and evaluation of antioxidant activities

\begin{tabular}{lcc}
\hline \multicolumn{1}{c}{ Solvent } & $\begin{array}{c}\text { Yield } \\
(\%)\end{array}$ & $\begin{array}{c}\text { Antioxidant } \\
\text { activity* }\end{array}$ \\
\hline Chloroform-1 & tr. & - \\
Chloroform-2 & 6.4 & 13 \\
Chloroform-3 & 24.2 & 18 \\
Chloroform/ & & \\
$\quad$ methanol (95: 5) & 37.5 & 17 \\
Methanol & 31.9 & 35 \\
Control & - & 4
\end{tabular}

* Length of the induction period of the substrate (days) at a $0.5 \%$ level, $45^{\circ} \mathrm{C}$.

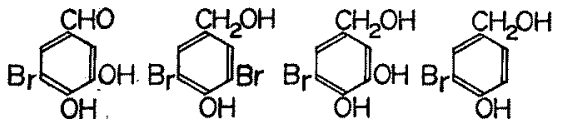
(1)
(2)
(3)
(4)

Fig. 1. Bromophenols found in the antioxygenic fraction of Polysiphonia urceolata.
Beilstein test. This suggests that the major antioxygenic compounds are similar to catechol and contained halogen. Because red algae of the family Rhodomelaceae, especially the genera Rhodemela, Odonthalia and Polysiphonia contain several kinds of bromophenols, ${ }^{\theta, 10}{ }^{2}$ it was thought that the antioxygenic principles in Polysiphonia lipids might be bromophenols. Therefore, the antioxygenic fraction was analyzed by GC-MS.

As a result, four bromophenols, shown in Fig. 1 , were identified in decreasing order of abundance by comparison with the data in the literatures. ${ }^{\theta, 10}$ The significant peaks $(\mathrm{m} / \mathrm{z})$ on MS are as follows:

(1) $362,360,347,345,273,271$.

(2) $428,426,424,411,409,407,347,345,337$, $335,333,147$.

(3) $436,434,424,411,409,347,345,337,345$, $333,331,259,257$.

(4) $348,346,267,259,257,147$.

As the peaks in (2) and (3) on GC were heavily overlapped, the exact composition of each bromophenols is not known, but the main component, (1), accounted for approximately $75 \%$ of the total content.

The bromophenol composition found in this work is exactly equal to that reported by Glombitza et al..$^{\theta)}$ However, Pedersen et al. ${ }^{\left.{ }^{\theta}\right)}$ found dibromo analogues of (1) and (3) as minor constituents besides major ones we found.

A wide variety of brominated organic compounds, including phenols, terpenoids and others ${ }^{10)}$ are known to be the characteristic constituents in red algae of the order Ceramiliales. In order to clarify the correlation between the antioxidant activity and occurrence of bromophenols in these algae, several algae of the family Rhodomelaceae were analyzed for antioxidant activity and qualitatively tested for bromophenols (TLC with ferric chloride reagent). Although the number of samples was limited, as shown in Table 3, two

Table 3. Antioxidant activities of the chloroformsoluble fractions of red algae in the family Rhodomelaceae

\begin{tabular}{|c|c|c|}
\hline \multirow[b]{2}{*}{ Species } & \multicolumn{2}{|c|}{ Antioxidant activity* } \\
\hline & $\begin{array}{l}\text { Acetone- } \\
\text { soluble fr. }\end{array}$ & $\begin{array}{l}\text { Acetone- } \\
\text { insoluble fr. }\end{array}$ \\
\hline Polysiphonia morrowii & 50 & 5 \\
\hline Polysiphonia urceolata & 53 & 3 \\
\hline Chondria crassicaulis & 3 & 3 \\
\hline Laurencia glandulifera & 6 & 3 \\
\hline
\end{tabular}


algae which contain bromophenols showed distinct antioxidant activities, while others which are known to contain terpenoids in place of phenols ${ }^{10)}$ were ineffective.

Although the antibiotic or growth regulating activities of bromophenols are well known, $, 0, \theta, 10)$ their excellent antioxidant activities are first noted in this work.

\section{Antioxidant Activities of Synthetic Bromophenols}

Two major bromophenols, BrPhenolCHO(1) and $\mathrm{BrPhenolCH}{ }_{2} \mathrm{OH}(3)$, were synthesized and their antioxidant activities were compared by four different methods with the following natural and synthetic antioxidants: $\alpha$-tocopherol, protocatechualdehyde, BHA and $N$-vanillyl octadecanamide (a synthetic tasteless homolog of capsaicin, the pungent principle in red pepper $^{7,11)}$ ).

In the oven test, both of the bromophenols were considerably effective and their activities were equivalent to that of $\mathrm{BHA}$ in dilute solutions. However, at $200 \mathrm{ppm}$, they were equal to that of vanillylamide but inferior to those of BHA and $\alpha$-tocopherol (Table 4).

Protocatechualdehyde, the non-brominated homolog of BrPhenolCHO, was also an excellent

Table 4. Comparison of antioxidant activities with the oven test

\begin{tabular}{|c|c|c|c|}
\hline \multirow{2}{*}{ Compound } & \multirow{2}{*}{$\begin{array}{l}\text { Concentra- } \\
\text { tion }\end{array}$} & \multicolumn{2}{|c|}{$\begin{array}{l}\text { Induction period } \\
\text { of the } \\
\text { substrate (days) }\end{array}$} \\
\hline & & $\begin{array}{c}\text { Me } \\
\text { ester of } \\
\text { safflower } \\
\text { oil }\end{array}$ & $\begin{array}{l}\text { Stripped } \\
\text { corn oil }\end{array}$ \\
\hline None (control) & - & 3 & 7 \\
\hline \multirow[t]{5}{*}{ BrPhenolCHO (1) } & $20 \mathrm{ppm}$ & 4 & \\
\hline & $50 \mathrm{ppm}$ & 7 & \\
\hline & $100 \mathrm{ppm}$ & 9 & \\
\hline & $200 \mathrm{ppm}$ & 11 & 21 \\
\hline & $1 \mathrm{mM}$ & & 22 \\
\hline \multirow[t]{2}{*}{ BrPhenolCH ${ }_{2} \mathrm{OH}(3)$} & $200 \mathrm{ppm}$ & & 20 \\
\hline & $1 \mathrm{mM}$ & & 21 \\
\hline \multirow[t]{2}{*}{$\alpha$-Tocopherol } & $200 \mathrm{ppm}$ & & 28 \\
\hline & $1 \mathrm{~mm}$ & & 31 \\
\hline \multirow[t]{2}{*}{ Protocatechualdehyde } & $200 \mathrm{ppm}$ & & 26 \\
\hline & $1 \mathrm{~mm}$ & & 25 \\
\hline \multirow[t]{5}{*}{ BHA } & $20 \mathrm{ppm}$ & 3 & \\
\hline & $50 \mathrm{ppm}$ & 4 & \\
\hline & $100 \mathrm{ppm}$ & 9 & \\
\hline & $200 \mathrm{ppm}$ & 21 & 37 \\
\hline & $1 \mathrm{~mm}$ & & 37 \\
\hline \multirow{2}{*}{$\begin{array}{l}N \text {-Vanillyl } \\
\text { octadecanamide }\end{array}$} & $200 \mathrm{ppm}$ & & 21 \\
\hline & $1 \mathrm{~mm}$ & & 18 \\
\hline
\end{tabular}

Table 5. Comparison of antioxidant activities with oxygen absorption in emulsion

\begin{tabular}{|c|c|c|c|}
\hline \multirow{2}{*}{ Compound } & \multirow{2}{*}{$\begin{array}{l}\text { Concentra- } \\
\text { tion in } \\
\text { emulsion } \\
\text { (ppm) }\end{array}$} & \multicolumn{2}{|c|}{$\begin{array}{l}\text { Antioxidant } \\
\text { activity* }\end{array}$} \\
\hline & & $\begin{array}{c}\text { Soybean } \\
\text { oil }\end{array}$ & $\begin{array}{l}\text { Stripped } \\
\text { corn oil }\end{array}$ \\
\hline None (control) & - & 7.8 & 4.5 \\
\hline \multirow[t]{4}{*}{ BrPhenolCHO (1) } & 0.02 & 16 & \\
\hline & 0.1 & 32 & \\
\hline & 0.2 & 74 & 7.9 \\
\hline & 1.0 & $>100$ & 8.1 \\
\hline \multirow{3}{*}{ BrPhenolC $\mathrm{H}_{2} \mathrm{OH}$ (3) } & 0.2 & & 5.5 \\
\hline & 0.4 & & 9.3 \\
\hline & 1.0 & & 12.2 \\
\hline \multirow[t]{2}{*}{$\alpha$-Tocopherol } & 0.2 & & 5.3 \\
\hline & 0.4 & & 5.8 \\
\hline \multirow[t]{3}{*}{ Protocatechualdehyde } & 0.2 & & 5.7 \\
\hline & 0.4 & & 6.0 \\
\hline & 1.0 & & 6.4 \\
\hline \multirow[t]{5}{*}{ BHA } & 0.02 & 17 & \\
\hline & 0.1 & 25 & \\
\hline & 0.2 & & 5.4 \\
\hline & 0.4 & & 7.5 \\
\hline & 1.0 & $>100$ & 8.6 \\
\hline$N$-Vanillyl & 0.2 & & 5.8 \\
\hline \multirow[t]{2}{*}{ octadecanamide } & 0.4 & & 7.5 \\
\hline & 1.0 & & 8.6 \\
\hline
\end{tabular}

Table 6. Comparison of antioxidant activities with the Active Oxygen Method

\begin{tabular}{|c|c|}
\hline Compound & Antioxidant activity* \\
\hline None (control) & 1.0 \\
\hline BrPhenolCHO (1) & 2.5 \\
\hline $\mathrm{BrPhenolCH}_{2} \mathrm{OH}(3)$ & 1.3 \\
\hline$\alpha$-Tocopherol & 7.0 \\
\hline Protocatechualdehyde & 6.1 \\
\hline BHA & 7.3 \\
\hline$N$-Vanillyl octadecanamide & 1.0 \\
\hline
\end{tabular}

Table 7. Comparison of antioxidant activities with the chemiluminescence method

\begin{tabular}{lc}
\hline \multicolumn{1}{c}{ Compound } & $\begin{array}{c}\text { Chemiluminescent } \\
\text { intensity } \\
\text { (counts/30 sec) }\end{array}$ \\
\hline None (control) & 6992 \\
BrPhenolCHO (1) & 5626 \\
BrPhenolCH $\mathrm{OH}_{2}(3)$ & 5777 \\
$\alpha$-Tocopherol & 4074 \\
Protocatechualdehyde & 6279 \\
BHA & 6681 \\
$N$-Vanillyl octadecanamide & 6574 \\
\hline
\end{tabular}


antioxidant and its effect was better than that of $\mathrm{Br}$ PhenolCHO. This phenolic aldehyde is known to be widely distributed as a minor constituent in plants, but its antioxidant activity has been overlooked.

The antioxidant activities in emulsion systems are shown in Table 5. In this condition, both of the bromophenols were very effective. Especially the effect of BrPhenolCHO was the most distinguished of all antioxidants examined. However, the problem with bromophenols of the catechol type in this system is the discoloration caused by reaction with iron.

Antioxidant activities evaluated with the AOM test are shown in Table 6. Bromophenols were less effective in this test because of their unstabilities at a high temperature $\left(97.8^{\circ} \mathrm{C}\right)$ in accordance with the previous observation. ${ }^{12)}$ Vanillylamide was ineffective because of its volatility.

The antioxidant activities for photosensitized oxidation, assayed by chemiluminescence, are shown in Table 7.

In the case of photooxidation, singlet oxygen is known to be the active oxygen species. It has also been reported ${ }^{13)}$ that a weak light mainly attributable to singlet oxygen is generated in the oxidation of vegetable oils. As a result, the effect of $\alpha$-tocopherol which has been known to be a quencher of singlet oxygen was the strongest of all samples. The activities of bromophenols were next, and better than that of BHA.

From these combined results, the properties of bromophenols as antioxidants have been clalified considerably. Bromophenols are excellent antioxidants at low temperature, especially in aqueous emulsion. However, their activities are very poor at higher temperatures. Although these bromophenols are natural compounds and the characteristic constituents in red algae, in order to apply these bromophenols as food antioxidants, detailed toxicity study will be required.

\section{Acknowledgements}

We thank Associate Professor K. Sekino, Tohoku University and Mr. T. NAKAJIMA for collecting algae. We are also grateful to Dr. K. OGAWA, Tohoku University for identification of algae. This work was supported in part by a Grant-in-Aid from the Ministry of Education, Science and Culture.

\section{References}

1) H. Ando and T. Kaneda: Eiyo To Shokuryo (J. Japan. Soc. Food Nutr.), 21, 245-248 (1968).

2) K. FuJimoto and T. Kaneda: Bull. Japan. Soc. Sci. Fish., 46, 1125-1130 (1980).

3) H. S. Olcotr and E. Einsetr: J. Am. Oil Chem. Soc. 35, 161-162 (1958).

4) H. Seino, S. WATANABE, and Y. ABE: Yukagaku, 20, 218-223 (1971).

5) R. PsCHORR: Ann. Chem., 391, 29-30 (1912).

6) K. W. Glombitza, H. Stoffelen, U. Murawski, J. Bielaczek, and H. EgGe: Planta Medica, 43, 105-114 (1974).

7) K. Fujmoto, Y. Kanno, and T. Kaneda: Yukagaku, 29, 419-422 (1980).

8) K. YAGI: Agric. Biol. Chem., 34, 142-145 (1970).

9) M. Pedersen, P. Saenger, and L. Fries: Phytochemistry, 13, 2273-2279 (1974).

10) Y. NAYA: Chem. Reviews (Japan), 25, 88-133 (1979).

11) K. Fujimoto, K. SekI, and T. Kaneda: Nippon Shokuhin Kogyo Gakkaishi, 21, 86-89 (1974).

12) R. UsuKI, Y. ENDo, and T. Kaneda: Nippon Shokuhin Kogyo Gakkaishi, 28, 583-587 (1981).

13) T. MiYazawa, R. Usuki, and T. Kaneda: Agric. Biol. Chem., 46, 1671-1672 (1982). 